\title{
Avaliação da Acurácia Posicional de Dados Gerados por Aeronave Remotamente Pilotada
}

\author{
Evaluation of Positional Accuracy of Data Generated Using Remotely \\ Piloted Aircraft
}

\author{
Dayanne Vieira de Oliveira ${ }^{1}$ \\ Jorge Luis Silva Brito ${ }^{2}$
}

Recebido em agosto de 2019. Aprovado em novembro de 2019.

\begin{abstract}
RESUMO
Aeronaves Remotamente Pilotadas (ARP) são equipamentos disponibilizados no mercado para obtenção de imagens aéreas de alta resolução. Diante do contexto de desenvolvimento dessa aeronave no meio civil, esta pesquisa teve como objetivo avaliar a acurácia posicional dos dados gerados a partir do uso da ARP PHANTOM 3 para fins de mapeamento topográfico e a possibilidade de utilização na cartografia cadastral. A metodologia compreendeu o planejamento de voo, seleção de 52 pontos de apoio coletados mediante levantamento pós-processado no modo estático através de receptores GNSS e nivelamento geométrico realizado com o Nível Digital DL-202 Ruide, criação de sinalizadores dos alvos e processamento fotogramétrico utilizando o software Pix4Dmapper Pro Trial. A avaliação da acurácia foi realizada no ortomosaico e MDT obtidos Sem pontos de controle (PC), com PC Distribuídos e PC Agrupados para a escala 1:1.000 através da análise de tendência, usando estatística inferencial, e da análise de precisão, por meio do teste Qui-Quadrado e do Decreto-Lei 89.817/ET-CQDG. Para comparar as discrepâncias obtidas entre dados posicionais de teste e de referência nas diferentes distribuições dos PC, utiliza-se a Análise de Variância e teste Tukey. Os resultados da acurácia posicional planimétrica foram aprovados para as imagens PC Distribuídos e PC Agrupados. O teste Tukey também apontou que essas imagens, PC Distribuídos e PC Agrupados, não diferem estatisticamente entre si. Portanto, concluiu-se que o uso da ARP utilizando PC pode ser considerado para mapeamento topográfico urbano em grande escala, sendo capaz de obter produtos planimétricos aceitáveis para gerar cartografia cadastral.
\end{abstract}

PALAVRAS-CHAVE: Imagens aéreas. Mapeamento Topográfico. Análise de tendência. Análise de precisão.

1Universidade Federal de Uberlândia. Programa de Pós-Graduação em Geografia, Brasil. E-mail: dayannevieira@ymail.com.

${ }^{2}$ Universidade Federal de Uberlândia. Programa de Pós-Graduação em Geografia, Brasil. E-mail: jbrito@ufu.br. 


\begin{abstract}
Remotely Piloted Aircraft (RPA) is of equipment available in the market to obtain high-resolution aerial imagery. Considering the rapid acceptance of this equipment in the civilian environment, this study aims to evaluate the positional accuracy of data obtained using a PHANTOM-3 for topographic mapping purposes and possibility of use in cadastral cartography. The methodology included: flight planning; the collection of 52 control points, collected through post-processing static positioning using GNSS receptors and geometric levelling using a Ruide DL-202 Digital Level; creation of target flags and photogrammetric processing using the software Pix4Dmapper Pro - Trial. The accuracy evaluation was performed using orthomosaic and DTM obtained: without the use of control points (PC); using distributed PC; and, using PC grouped to the scale of 1:1.000 through tendency analysis, using inferential statistics, and precision analysis, through the Chi-Square test and the decree-law 89.817/ET-CQDG. In order to compare the discrepancies obtained between the test positional data and the reference data in different distributions of the PC, it was used the Analysis of Variance and the Tukey test. The results obtained regarding the planimetric positional accuracy were approved for the images Distributed PC and Grouped PC. In addition, the Tukey test pointed out that these images do not differ statistically from each other. Therefore, RPA using PC might be used for large scale urban topographic mapping, once it is capable of providing products planimetric with acceptable cartographic standards to generate cadastral cartography.
\end{abstract}

KEYWORDS: Aerial imagery. Topographic mapping. Tendency analysis. Precision analysis.

\title{
1 Introdução
}

Segundo dados disponíveis pelo Instituto Brasileiro de Geografia e Estatística (IBGE, 2015), o Brasil possuía até 31/12/2014, um total de 67 milhões de parcelas urbanas, ocupando 5407700 ha (FARIAS et al., 2017), totalizando menos de $1 \%$ da área territorial e concentrando $84,3 \%$ da população. Dos 5570 municípios a estimativa de residentes nos de pequeno porte, em 01/07/2017, aponta que 68,3\% possuem até 20 mil habitantes (IBGE, 2017). No entanto, uma quantidade expressiva desses imóveis ainda não possui registro em Banco de Dados Georreferenciado (BDG).

Mesmo ante avanços legais, com planos diretos participativos, instrumentos urbanísticos previstos no Estatuto da Cidade (Lei 10.257/2001), a Portaria Ministerial N 511/2009 do Ministério das Cidades normatizando a criação, instituição e atualização do Cadastro Técnico Multifinalitário 
(CTM) nos municípios brasileiros, com o Decreto 8764/2016 que dispõe sobre o Sistema Nacional de Gestão de Informações Territoriais (SINTER) e o Decreto 9310/2018 que institui os procedimentos aplicáveis à Regularização Fundiária Urbana e determina o levantamento topográfico georreferenciado para os limites das unidades imobiliárias, muitas descrições ainda são caraterizadas pela precariedade de informações, não coincidência a sua realidade e conflitos de informações. $\mathrm{Na}$ maioria das cidades, principalmente nas de pequeno porte, o funcionamento do cadastro na prefeitura ainda é composto por trabalhos manuais e com o auxílio mínimo de tecnologia.

Diante do exposto, além da implantação de legislações é importante verificar métodos de obtenção de dados para compor o mapeamento urbano, avaliar as diversas tecnologias existentes e escolher aquela que melhor se aplica para atingir as determinadas especificações de acurácia.

As Aeronaves Remotamente Pilotadas (ARP) são exemplos de equipamentos disponibilizados no mercado para obtenção de imagens aéreas de alta resolução. Segundo Eick (2010), o uso dessa tecnologia aumentou nos campos militar e inteligência e são cada vez mais utilizadas no setor civil.

No Brasil, a regulamentação das operações de aeronaves não tripuladas entrou em vigor em 03/05/2017, desde então, até abril de 2018, 41338 veículos aéreos não tripulados foram cadastrados por meio do Sistema de Aeronaves não Tripuladas (SISANT), gerenciado pela Agência Nacional de Aviação Civil (ANAC). Dessas, 26843 são de uso recreativo e 14855 destinamse ao uso profissional (ANAC, 2018).

Nesse contexto de desenvolvimento no meio civil surgiram diversas aplicações do potencial desse veículo para mapear diferentes alvos, inclusive alguns estudos no Brasil e no exterior mostram a capacidade da ARP em obter dados para mapeamento topográfico com o objetivo de gerar cartografia cadastral, como em Rijsdijk et al. (2013); Volkmann e Barnes (2014); Antunes e Hollatz (2015); Pelegrina et al. (2016); e Fonseca Neto et al. (2017).

Assim, considera-se a ARP com potencial para se tornar uma alternativa para o mapeamento topográfico em grande escala para aquisição 
de dados dos imóveis urbanos. Visto que, além do alto custo, outra problemática para o uso de estação total é a delimitação do imóvel por um muro, na qual impede a visada dos vértices localizados no fundo do imóvel. Por outro lado, os métodos de posicionamento GNSS (Global Navigation Satellite Systems), como por RTK (Real-time Kinematic) possibilitam medir inúmeros pontos em um curto intervalo de tempo, mas nem sempre cumprem todas as tarefas, devido as eventuais perdas de sinais. Dessa forma, é importante buscar por soluções em termos de tecnologias e técnicas que possibilitem a acurácia de delimitação de imóveis urbanos e ao mesmo tempo rapidez e economia no levantamento de dados de modo a permitir implantação e atualização do CTM principalmente em cidades de pequeno porte.

Ante da realidade apresentada o presente trabalho investigou 0 desempenho e a qualidade dos produtos gerados por uma ARP de baixo custo para elaboração de mapeamento topográfico em grande escala e a possibilidade de utilização na cartografia cadastral. Em geral, o mapeamento topográfico é a representação do território através de mapas e pode ser utilizado para o posicionamento no espaço geográfico, suporte a outros mapeamentos (como o cadastral), planejamento urbano, ambiental, estabelecimento de limites legais e de propriedade da terra, entre outros (IBGE, 2018). Quando em grande escala refere-se à representação de feições com alto nível de detalhamento, que no Brasil, a Especificação Técnica para Aquisição de Dados Geoespaciais Vetoriais de Defesa da Força Terrestre (ETADGV) (BRASIL, 2011) considera nesse sentido escalas maiores que 1:10.000.

Para atingir os objetivos, verificou-se a acurácia planialtimétrica do levantamento aerofotogramétrico com ARP através de pontos de controle présinalizados, analisou-se os ortomosaicos gerados sem pontos de controle através das fotos obtidas pela ARP, realizou-se uma análise comparativa dos dados espaciais obtidos por meio da ARP com os dados adquiridos através do uso de receptores GNSS e nível, investigou-se através de análise de tendência e teste de precisão se a escala obtida é viável para geração e atualização do mapeamento topográfico em grande escala. 


\section{Acurácia Posicional}

Diversas normas foram desenvolvidas com o objetivo de estabelecer métodos de análise para avaliar o produto cartográfico, verificando assim a sua acurácia posicional. No Brasil, essa avaliação é regulamentada pelo Decreto-lei n 89817, de 20/06/1984 (BRASIL, 1984) e complementada pelas especificações técnicas elaboradas pela Divisão do Serviço Geográfico (DSG) em conformidade com a INDE (Infraestrutura Nacional de Dados Espaciais).

Com o aumento do uso dos produtos cartográficos digitais, em 2011, foi elaborada pela DSG a especificação que padroniza a aquisição da geometria dos dados geoespaciais vetoriais intitulada ET-ADGV (BRASIL, 2011). Em 2016 com o objetivo de fornecer uma forma padronizada para avaliar a qualidade dos produtos de conjuntos de dados geoespaciais integrantes do Sistema Cartográfico Nacional (SCN) surgiu a ET-CQDG (Especificação Técnica Para Controle de Qualidade de Dados Geoespaciais) (BRASIL, 2016).

O Decreto-lei $\mathrm{n}^{\circ} 89817$ estabelece no artigo $8^{\circ}$ critérios para classificação de cartas utilizando como parâmetros um indicador estatístico, denominado de Padrão de Exatidão Cartográfica (PEC), também considera os termos Desvio Padrão (DP), Erro Padrão (EP) e Erro Quadrático Médio (EQM) como sinônimos, bem como os termos acurácia e exatidão (BRASIL, 1984). Sendo assim, os termos Acurácia Posicional Absoluta (APA) e Exatidão Cartográfica (EC) referenciam a avaliação da acurácia ou exatidão de um produto cartográfico, sendo o DP (ou EP ou EQM) uma de suas componentes.

Para o estudo da acurácia posicional em dados espaciais é fundamental conhecer os erros causados na manipulação de dados. Segundo Gemael (1994), qualquer medida está sujeita a erros aleatórios, sistemáticos ou grosseiros. Os erros grosseiros são devidos a falha humana ou método errado de medição (FAN, 2010). Os erros sistemáticos são causados por fontes conhecidas (instrumento de medida, método de observação e causas ambientais) e que podem, em geral, ser eliminados ou compensados (DALMOLIN, 2004). Já os erros aleatórios são de causas diferentes e incoerentes, bem como causas 
temporais que variam durante observações sucessivas, sendo imprevisível sua ocorrência (GHILANI e WOLF, 2006).

Geralmente, o erro grosseiro pode ser eliminado quando detectado, assim a acurácia incorpora erros sistemáticos, tendência, e erros aleatórios, precisão. Segundo Mikhail e Ackerman (1976) a acurácia é a dispersão no entorno do valor real e a precisão é a dispersão no entorno da média. Assim, a precisão está vinculada apenas aos efeitos aleatórios ao passo que a acurácia vincula-se com os efeitos sistemáticos e aleatórios (tendência e precisão) (GEMAEL, 1994).

\section{Materiais e métodos}

3.1 Área de estudo

A área de estudo está localizada no campus Glória da Universidade Federal de Uberlândia, a sudeste do município de Uberlândia/MG (Figura 1). Essa área foi selecionada por possuir uma variedade de alvos, envolver construções prediais e vias, além de se adequar à discussão da legislação brasileira de ARP.

Figura 1 - Área de estudo

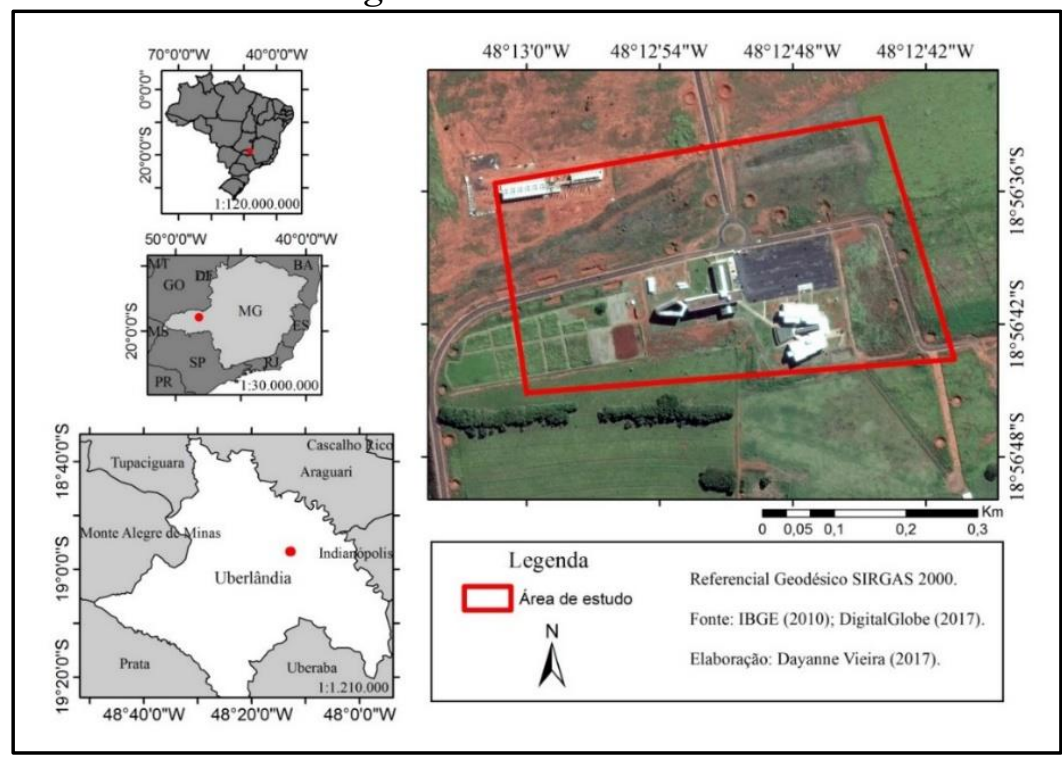

Fonte: Elaborada pelos autores. 
3.2 Materiais utilizados

Os materiais utilizados para execução desse projeto foram:

a) Uma ARP modelo multirrotor DJI PHANTOM 3 ADVANCED (Classe 3), do tipo quadricóptero, tempo de voo máximo de 23 minutos, operado por rádio controle, possui embarcado sistema inercial, receptor de sinais de satélite de posicionamento - GNSS (posicionamento absoluto por código) que conecta com os satélites GPS e GLONASS, sensor óptico Sony EXMOR 1/2, 3" que captura fotos em 12 megapixels, lente FOV 94º, distância focal de $20 \mathrm{~mm}$ (equivalente ao formato $35 \mathrm{~mm}$ ) f/2.8 (DJI, 2015);

b) Um receptor GNSS ProMark 100 com precisão de 0,5 cm + 1ppm pósprocessado; um receptor ProMark 200 com precisão horizontal estática de 0,5 cm + 0,5ppm; um Nível Digital DL-202 Ruide com precisão 1,5mm no duplo nivelamento por $\mathrm{Km}$, duas miras com código de barras e sapatas;

c) Pré-sinalizadores dos pontos de controle (PC);

d) Software GNSS Solution para pós-processamento dos dados coletados pelos receptores GNSS ProMark 100 e 200; Software QGis 2.16.3 para planejamento dos pontos de apoio, tratamento dos dados e produção de layout de mapas; Aplicativo gratuito Pix4D Capture para o planejamento, execução e acompanhamento do voo; Software Pix4Dmapper Pro - Trial versão teste para processamento das imagens e geração do ortomosaico, modelo digital de superfície (MDS) e modelo digital do terreno (MDT).

Os equipamentos e softwares foram disponibilizados pelo Laboratório de Cartografia e Sensoriamento Remoto do Instituto de Geografia/UFU e pelo Laboratório de Topografia da Faculdade de Engenharia Civil/UFU.

\subsection{Metodologia}

A Figura 2 indica o fluxograma com todas as etapas e procedimentos metodológicos que foram seguidas na pesquisa para atingir os objetivos propostos. 
Figura 2 - Fluxograma da metodologia adotada

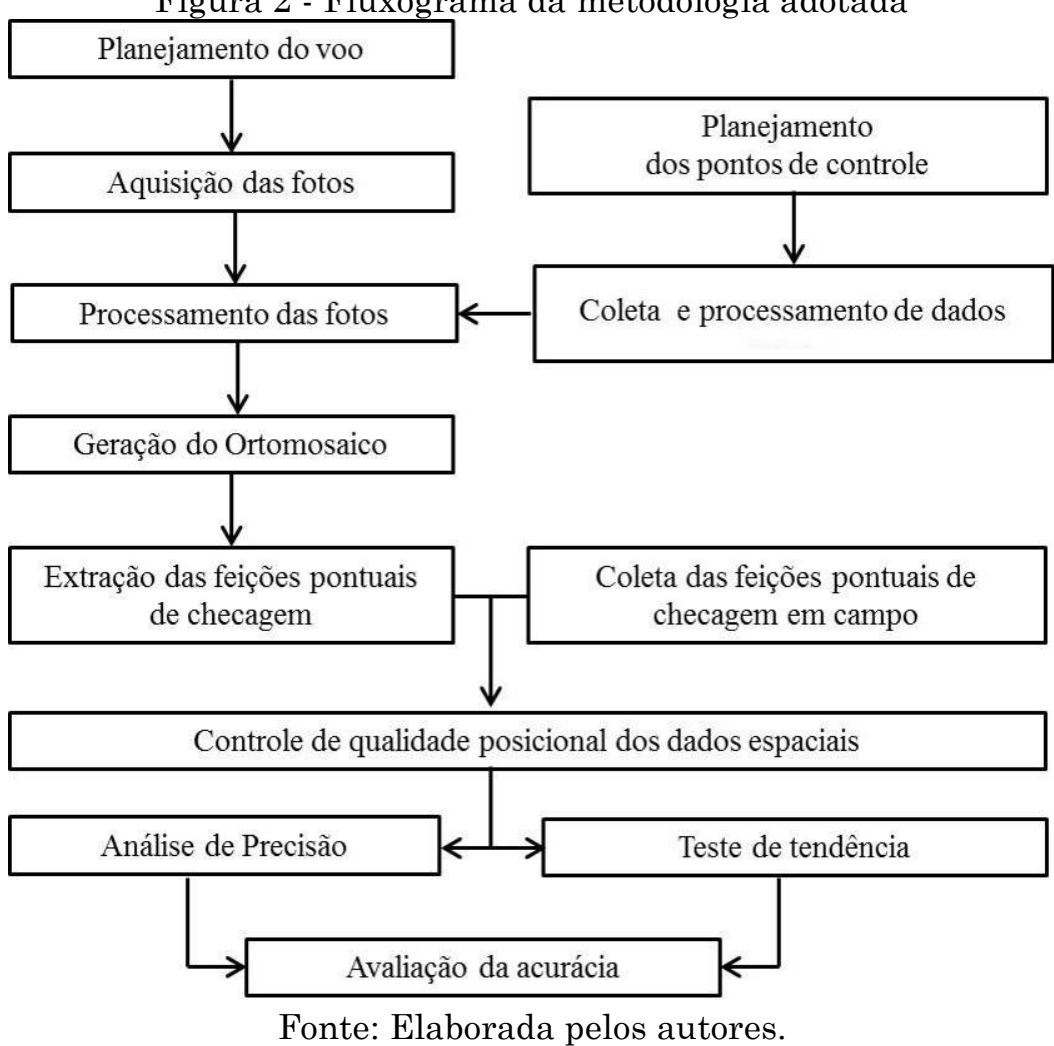

$\mathrm{Na}$ etapa de planejamento de voo foi realizado a análise do local para lançamento e pouso da aeronave. A ARP utilizada não possui raio de operação, no entanto o DECEA (Departamento de Controle do Espaço Aéreo) exige operar em condições VMC (condições meteorológicas de voo visual) e VLOS (linha de visada visual), afastado no máximo 500m horizontalmente do piloto.

No aplicativo Pix4D Capture foi delimitada uma área de 8,224 ha que cobre a área pretendida e gera uma margem de segurança, visando evitar distorção nas bordas das imagens. Para garantir o recobrimento entre as fotos e permitir a geração de modelos estereoscópicos foi utilizada sobreposição lateral e longitudinal de $80 \%$ e altura de voo de $80 \mathrm{~m}$. Esse valor de altura foi definido considerando o tempo de voo, visto que o máximo previsto pela DJI (2015) é de 23 minutos.

O momento ideal para realização do levantamento ficou na dependência das condições climáticas, uma vez que o PHANTOM 3 ADVANCED não pode realizar voo diante de chuva e de velocidade do vento 
maior que $10 \mathrm{~m} / \mathrm{s}$. Assim, o dia 21/12/2017 às 10 horas, com velocidade do vento de $7 \mathrm{~m} / \mathrm{s}$, apresentou condições climáticas que permitisse a realização do voo.

Os pontos de apoio, controle (PC) e verificação (PV), foram distribuídos por toda área de interesse de forma visual, sem o uso de técnicas de análises espaciais para verificar o padrão de distribuição. Por isso, a análise da acurácia posicional para a área de estudo é realizada em três imagens distintas geradas no software Pix4Dmapper Pro - Trial, sendo Sem PC, com 8 PC Distribuídos e com 8PC Agrupados. Foram planejados 52 pontos de apoio, que foram sinalizados e coletados informações com os receptores GNSS para obtenção da latitude e longitude e com o nível digital para obtenção da altitude. Para a imagem Sem PC, foram planejados os 52 pontos como sendo PV; para a imagem com PC Distribuídos, foram planejados 8 PC (Figura 3); para a imagem com PC Agrupados, foram planejados 8PC (Figura 4).

Figura 3 - Ortomosaico gerado com 8 pontos de controle distribuídos

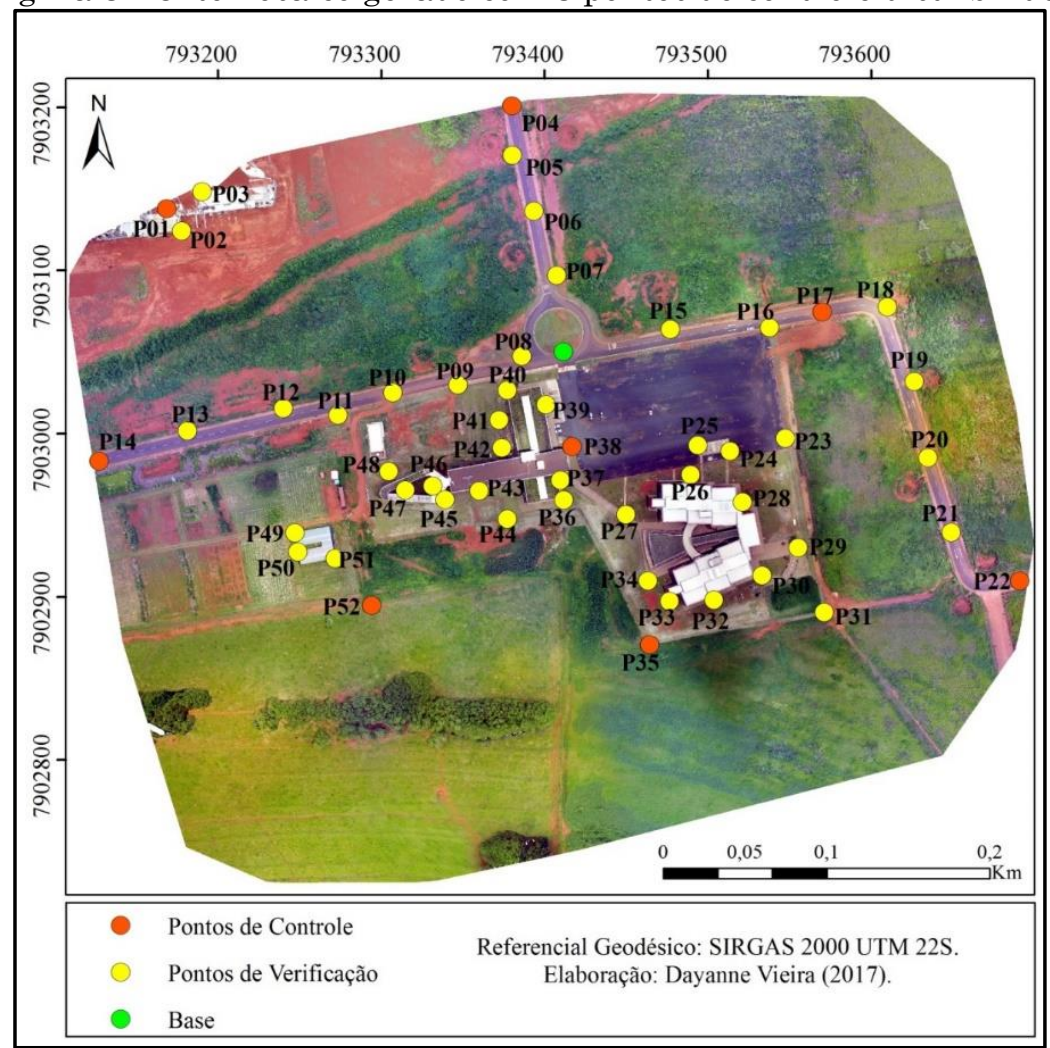

Fonte: Elaborada pelos autores. 
Figura 4 - Ortomosaico gerado com 8 pontos de controle agrupados

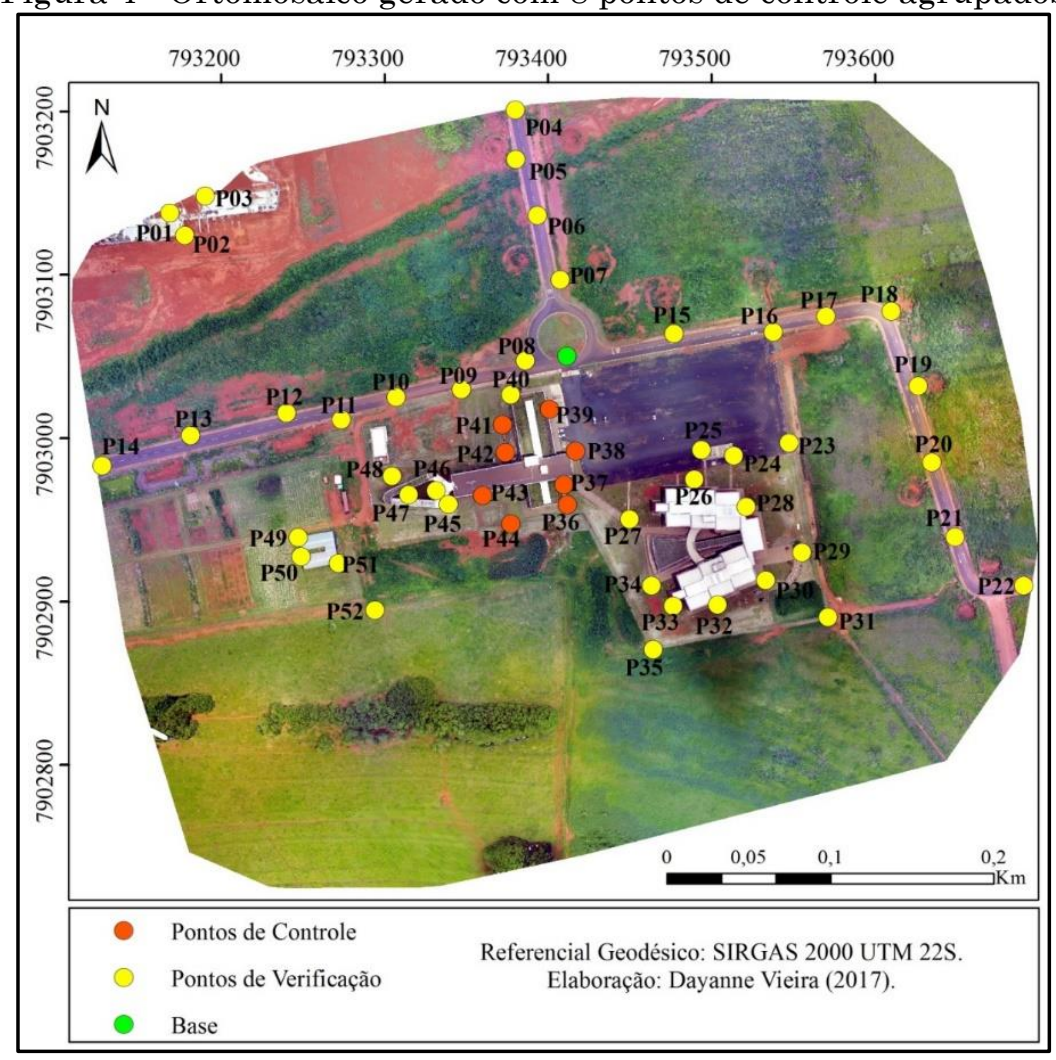

Fonte: Elaborada pelos autores.

Para sinalização dos alvos foram usados sinalizadores artificiais e naturais (Figura 5). Os artificiais foram feitos com papel cartão medindo 30x30cm (relacionado ao GSD). Como alvos naturais foram usados canto das faixas interrompidas das vias, das caixas de passagem e intersecções visíveis.

Figura 53 - Visualização dos sinalizadores artificial de alvo (a) e dos alvos naturais (b, c, d)

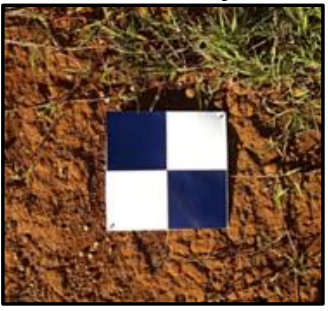

(a)

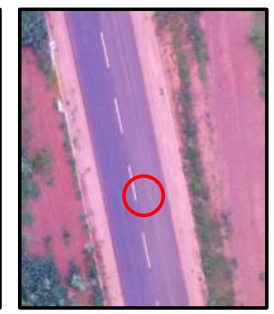

(b)

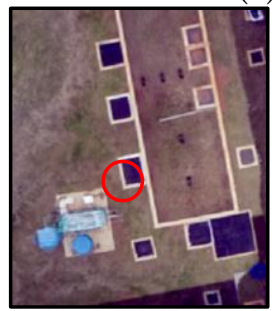

(c)

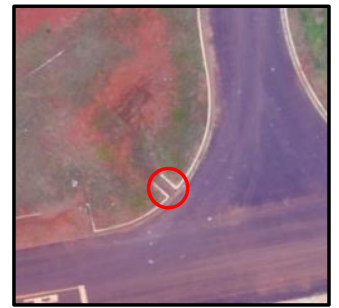

(d)

Fonte: Elaborada pelos autores.

O voo realizado registrou 273 fotografias e o processamento fotogramétrico foi feito no software Pix4Dmapper Pro - Trial, com entrada das fotos e das coordenadas dos PC, Este, Norte (levantamento no modo 
estático) e altitude ortométrica (nivelamento geométrico - nesse processo as altitudes da plataforma utilizada foram transformadas em ortométrica) e resultou no MDS, MDT e Ortomosaico (Figura 6).

(a)

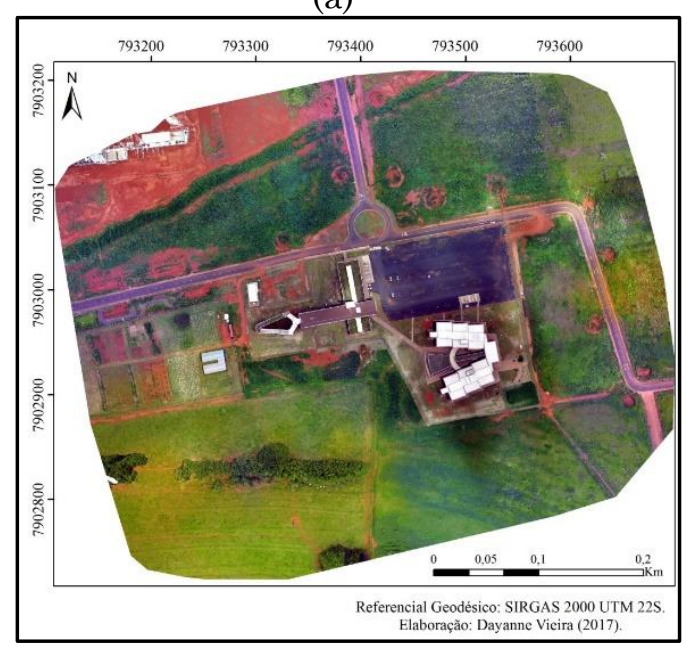

Figura 64 - (a) Ortomosaico; (b) MDS; (c) MDT

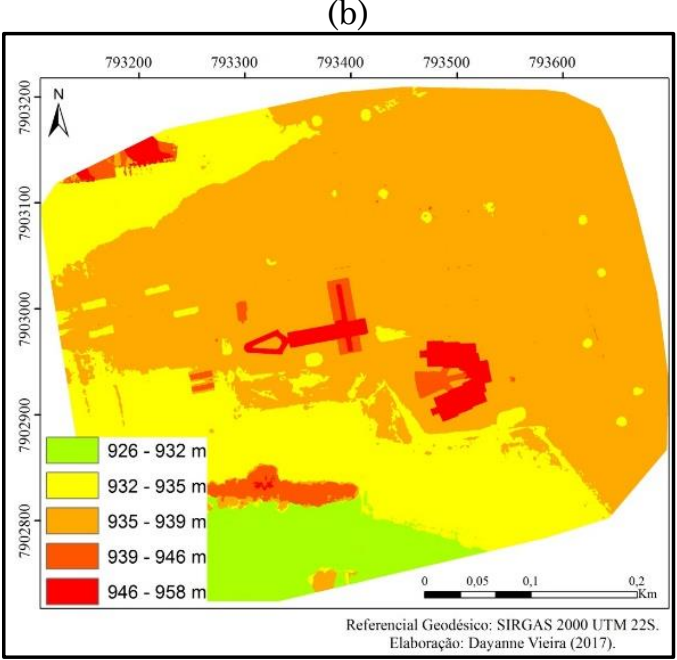

(c)

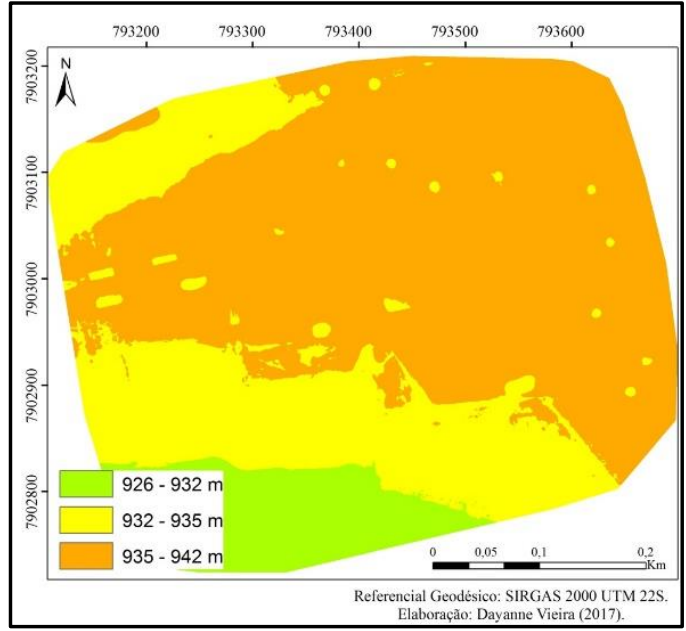

Fonte: Elaborada pelos autores.

No processamento fotogramétrico inicial foi realizado: Identificação nas imagens de pontos homólogos; Encontro das imagens que têm os mesmos pontos-homólogos; Calibração dos parâmetros internos (distância focal da câmara, ponto principal, coeficientes de distorção radial simétrica e de distorção descentrada) e externos da câmara (utilizou além dos parâmetros internos da câmera, os pontos de controle adquiridos); Localização do modelo, através de informações georreferenciadas. 
O processamento realizado cumpriu todos os parâmetros de forma satisfatória, a distância focal calibrada foi de $3,723 \mathrm{~mm}$; coordenada do ponto principal X de 3,207 mm e Y de 2,330mm; os coeficientes de distorção descentrada $T_{1}$ e $T_{2}$ igual a 0 ; os coeficientes de distorção radial simétrica $R_{1}$, $R_{2}, R_{3}$ igual a $-0,008 ; 0,007 ; 0,007$ respectivamente, todas imagens foram calibradas em um bloco, a diferença relativa entre os parâmetros internos e otimizados da câmera foi 3,21\%, o erro médio (RMS) dos PC de 0,03m, sendo o erro médio entre as coordenadas do centro ótico da câmera fornecida pelo sistema de posicionamento da ARP e o obtido ao utilizar os PC nas imagens de $0,01 \mathrm{~m}$ no eixo $\mathrm{X}, 0,02 \mathrm{~m}$ no eixo Y e $0,09 \mathrm{~m}$ no eixo Z, e GSD de 3,96 cm.

O levantamento pós-processado no modo estático foi realizado utilizando receptores GNSS ProMark 200 e 100, como base e rover, com taxa de coleta de 15" e máscara de elevação de $10^{\circ}$. Foram necessários 6 dias para executá-lo, a base rastreou um total de 38 horas e o rover cada ponto por 30 minutos. Os pontos de apoio (PC e PV) coletados foram processados no software GNSS Solutions e obtiveram erro médio de $0,02 \mathrm{~m}$ no eixo X, 0,02m no eixo $\mathrm{Y}$ e $0,04 \mathrm{~m}$ no eixo $\mathrm{Z}$.

Para obtenção das altitudes dos pontos de apoio foi realizado o nivelamento geométrico. A Referência de Nível $(\mathrm{RN})$ usada possui altitude ortométrica de 935,379m e foi implantada pela empresa R\&V Engenharia LTDA. Primeiramente, realizou o transporte da altitude conhecida (RN) para o ponto denominado Base, em um trecho de $713 \mathrm{~m}$ de nivelamento e contranivelamento. A partir da altitude da Base conhecida, foram realizadas 6 seções de nivelamento para o cálculo dos demais pontos de apoio, com comprimentos das visadas de ré e de vante aproximadamente iguais e de, no máximo, 80 m, executado segundo a NBR 13.133/94.

De posse das imagens (ortomosaicos e MDT) parte-se para a avaliação da acurácia posicional. A acurácia se refere tanto a efeitos aleatórios quanto a efeitos sistemáticos, assim a análise da acurácia é a junção da análise de tendência e da análise de precisão. A Figura 7 apresenta as etapas para a avaliação da acurácia posicional dos ortomosaicos e MDT gerados. 
Figura 7 - Etapas para a avaliação da acurácia posicional

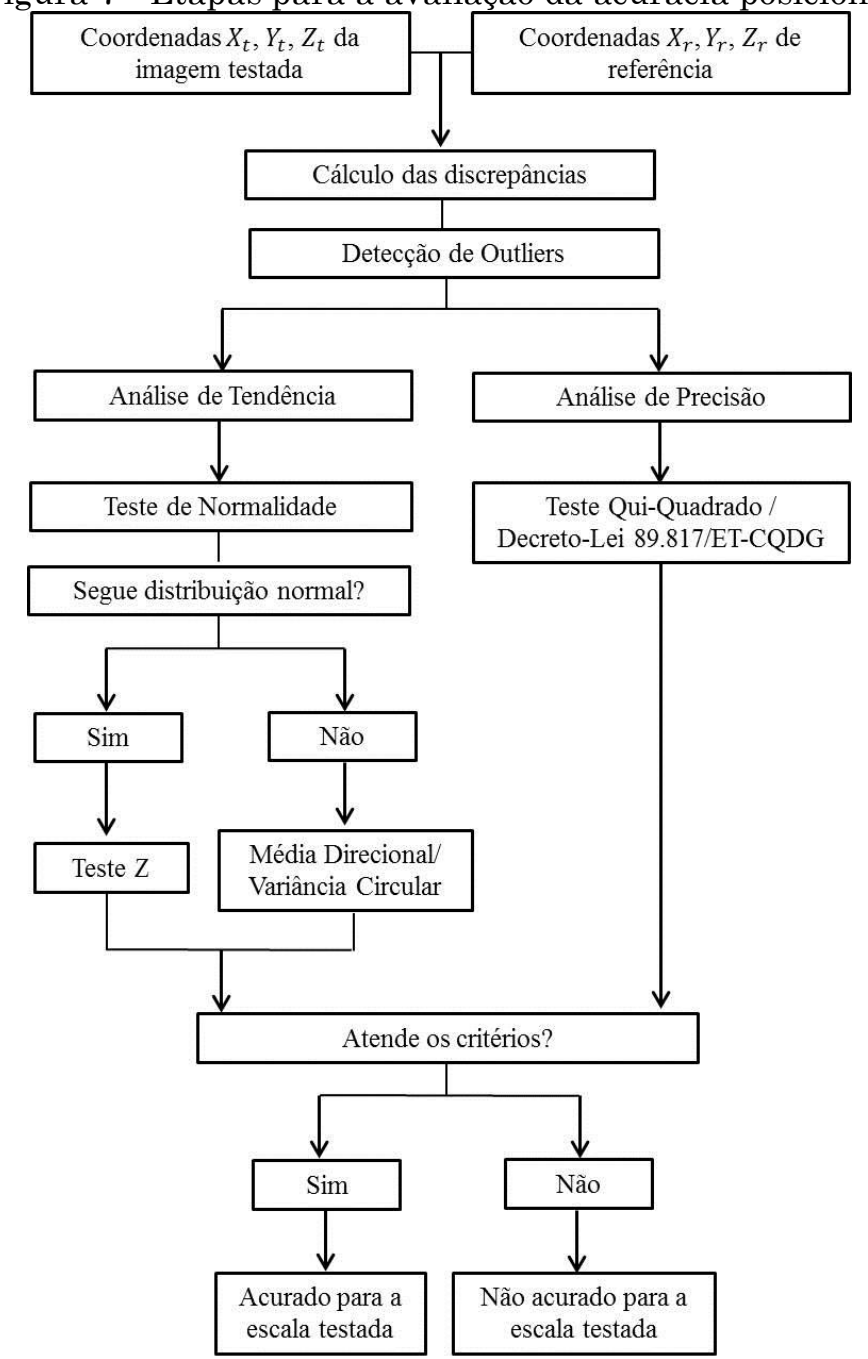

Fonte: Elaborada pelos autores.

Após geração das imagens e coleta dos dados posicionais de referência (coordenadas dos pontos de apoio obtidas no levantamento modo estático e nivelamento geométrico) e de teste (coordenadas extraídas das imagens) realiza-se o cálculo das discrepâncias e análise de detecção de outliers usando o diagrama Boxplot (MONTGOMERY e RUNGER, 2002).

Para análise de tendência, se os dados seguirem distribuição normal utiliza-se o teste $\mathrm{t}$ ou Z, caso contrário usa-se Média Direcional aliada a Variância Circular. Por isso, é realizada o teste de normalidade dos dados de Kolmogorov-Smirnov, segundo Gibbons e Chakraborti (2003). Caso todas as amostras sigam distribuição normal, na análise de tendências utiliza-se a estatística inferencial, ou seja, realiza-se o teste t ou Z. Segundo Montgomery 
e Runger (2002), para amostra com mais de 30 elementos é recomendado teste Z. Dessa forma, nesse trabalho, realizam-se análise de tendência baseados na distribuição Z, aplicando nível de confiança $(1-\alpha)$ igual a 90\% $(\alpha=0,1)$.

A análise de precisão segundo Galo e Camargo (1994), pode ser feita através do padrão de acurácia posicional, nesse caso usou-se o padrão brasileiro descrito pelo Decreto-lei 89.817/ET-CQDG (BRASIL, 2016) e o teste de qui-quadrado proposto por Galo e Camargo (1994).

Aplicadas as metodologias apresentadas, se o dado espacial avaliado for aprovado em todas as análises de tendência e precisão, este dado será considerado acurado para a escala e a classe testada.

Para comparar as discrepâncias obtidas nas diferentes distribuições dos PC aplicou-se Análise de Variância (ANOVA) e Teste Tukey. A ANOVA, segundo Hair Júnior et al. (2009), permite verificar a existência de diferenças entre grupos e determina se as médias de grupos diferem significativamente, no entanto não indica entre quais grupos a diferença é significativa. Assim, se faz necessário utilizar testes de comparações múltiplas, como o Teste Tukey, que consiste em determinar a menor diferença significativa entre a média de dois grupos (MONTGOMERY e RUNGER, 2002).

\section{Resultados e discussões}

Por meio dos dados dos PV coletados avaliou-se a acurácia posicional planimétrica e altimétrica das imagens Sem PC, 8 PC Distribuídos e 8 PC Agrupados obtidas na escala de 1:1000. No contexto do mapeamento topográfico em grandes escalas para aplicações na cartografia cadastral, os erros devem ser menores para não comprometer a determinação da localização do imóvel. Assim, recomenda-se acurácia compatível com classe A.

O resultado obtido no cálculo das discrepâncias é apresentado nas Figuras 8, 9 e 10. As maiores discrepâncias foram nas imagens Sem PC, em todos os grupos na componente $\mathrm{Z}$ e nas imagens com $\mathrm{PC}$ em locais em que não foram inseridos PC no processamento. 
Figura 85 - Discrepâncias observadas para o ortomosaico e MDT Sem PC

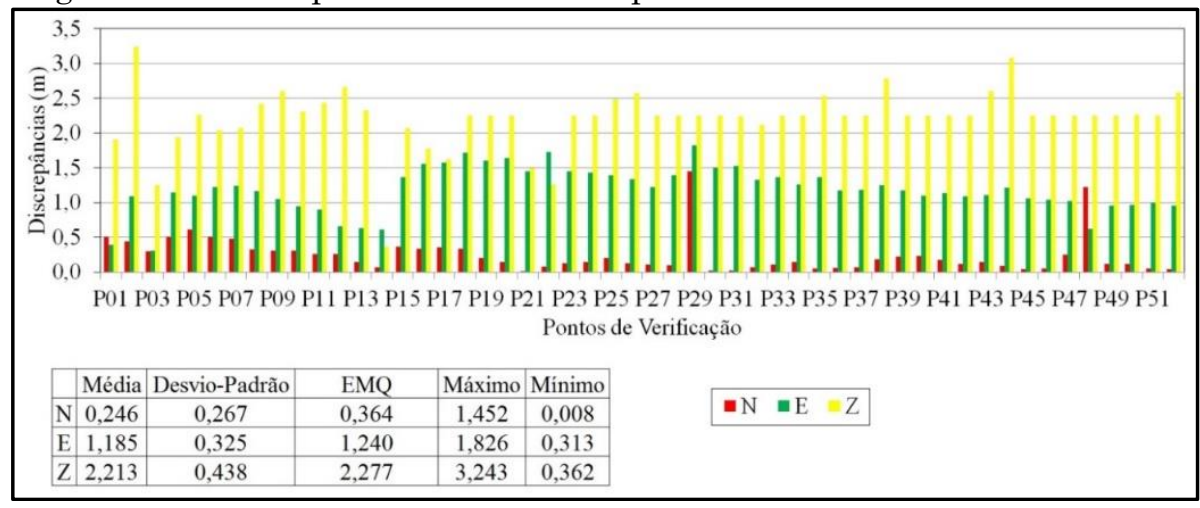

Fonte: Elaborada pelos autores.

Figura 9 - Discrepâncias observadas para o ortomosaico e MDT com PC Distribuídos

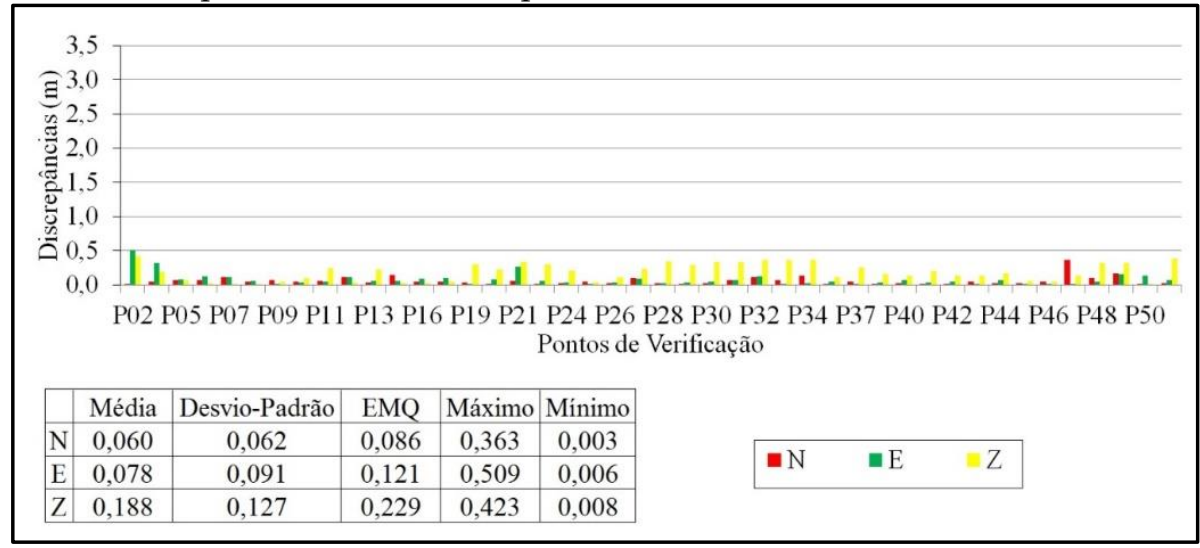

Fonte: Elaborada pelos autores.

Figura 10 - Discrepâncias observadas para ortomosaico e MDT com PC Agrupados

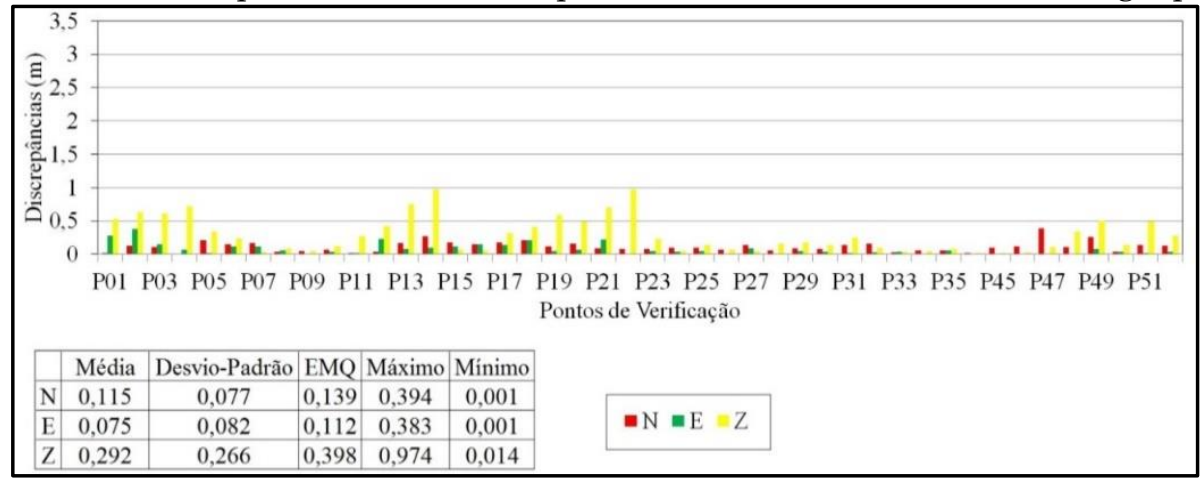

Fonte: Elaborada pelos autores.

$\mathrm{Na}$ deteç̧ão de outliers (Figura 11), nas imagens Sem PC foram detectados 5 outliers na componente planimétrica e 21 na altimétrica. Nas imagens com 8 PC Distribuídos foram detectados 4 na componente planimétrica e 2 na altimétrica. Nas imagens com 8 PC Agrupados foram detectados 2 na componente planimétrica e 3 na componente altimétrica. 
Figura 116 - Boxplot das discrepâncias posicionais planimétricas e altimétricas
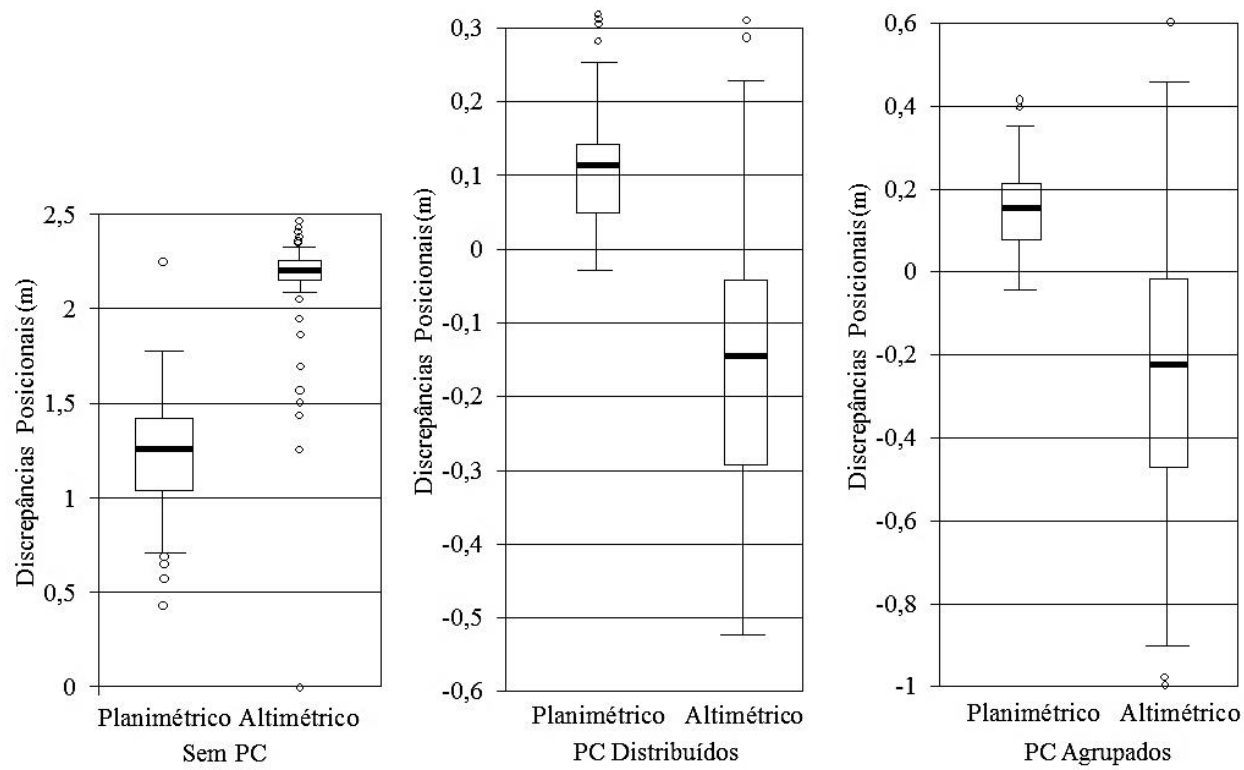

Fonte: Elaborada pelos autores.

Com a amostra sem a presença de outliers, aplicou-se o teste QuiQuadrado (GALO e CAMARGO, 1994), apresentados na Tabela 1.

Tabela 1 - Resultado do teste Qui-Quadrado

\begin{tabular}{|c|c|c|c|c|c|c|c|c|c|}
\hline \multirow{6}{*}{ 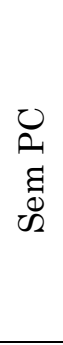 } & \multirow{3}{*}{ Plan. } & \multirow[b]{2}{*}{ Escala } & \multirow[b]{2}{*}{ Classe } & \multirow[b]{2}{*}{$\begin{array}{l}\mathrm{EP} \\
(\mathrm{m})\end{array}$} & \multirow[b]{2}{*}{$\mathrm{X}^{2}$ Tabelado } & \multicolumn{2}{|c|}{$\mathrm{X}^{2}$} & \multirow{2}{*}{$\begin{array}{c}\text { Condição } \\
X^{2} \leq \\
X^{2} \text { Tabelado }\end{array}$} & \multirow[b]{2}{*}{ Classificação } \\
\hline & & & & & & $\mathrm{N}$ & $\mathrm{E}$ & & \\
\hline & & $1: 1.000$ & $\mathrm{~A}$ & 0,17 & 59,774 & 187,02 & 408,22 & Falso & Reprovado \\
\hline & \multirow{3}{*}{ Alt. } & \multirow[b]{2}{*}{ Escala } & \multirow[b]{2}{*}{ Classe } & \multirow[b]{2}{*}{$\begin{array}{l}\mathrm{EP} \\
(\mathrm{m})\end{array}$} & \multirow[b]{2}{*}{$\mathrm{X}^{2}$ Tabelado } & \multicolumn{2}{|c|}{$\mathrm{X}^{2}$} & Condições & \\
\hline & & & & & & \multicolumn{2}{|c|}{$\mathrm{Z}$} & $\begin{array}{c}\mathrm{X}^{2} \leq \\
\mathrm{X}^{2} \text { Tabelado }\end{array}$ & Classificação \\
\hline & & $1: 1.000$ & $\mathrm{~A}$ & 0,17 & 40,256 & \multicolumn{2}{|c|}{2,06} & Verdadeiro & Aprovado \\
\hline \multirow{6}{*}{ Oे } & \multirow{3}{*}{ Plan. } & \multirow[b]{2}{*}{ Escala } & \multirow[b]{2}{*}{ Classe } & \multirow[b]{2}{*}{$\begin{array}{l}\text { EP } \\
(\mathrm{m})\end{array}$} & \multirow[b]{2}{*}{$\mathrm{X}^{2}$ Tabelado } & \multicolumn{2}{|c|}{$\mathrm{X}^{2}$} & Condição & \multirow[b]{2}{*}{ Classificação } \\
\hline & & & & & & $\mathrm{N}$ & $\mathrm{E}$ & $\begin{array}{c}\mathrm{X}^{2} \leq \\
\mathrm{X}^{2} \text { Tabelado }\end{array}$ & \\
\hline & & $1: 1.000$ & $\mathrm{~A}$ & 0,17 & 51,805 & 12,03 & 12,74 & Verdadeiro & Aprovado \\
\hline & \multirow{3}{*}{ Alt. } & \multirow[b]{2}{*}{ Escala } & \multirow[b]{2}{*}{ Classe } & \multirow{2}{*}{$\begin{array}{l}\mathrm{EP} \\
(\mathrm{m})\end{array}$} & \multirow[b]{2}{*}{$\mathrm{X}^{2}$ Tabelado } & \multicolumn{2}{|c|}{$\mathrm{X}^{2}$} & Condição & \multirow[b]{2}{*}{ Classificação } \\
\hline & & & & & & \multicolumn{2}{|c|}{ Z } & $\begin{array}{c}\mathrm{X}^{2} \leq \\
\mathrm{X}^{2} \text { Tabelado }\end{array}$ & \\
\hline & & $1: 1.000$ & $\mathrm{~A}$ & 0,17 & 54,090 & 24 & 57 & Verdadeiro & Aprovado \\
\hline & & & & & & $\bar{X}$ & $2^{2}$ & Condição & \\
\hline$\frac{n}{0}$ & Plan. & Escala & Classe & $\begin{array}{l}\mathrm{EP} \\
(\mathrm{m})\end{array}$ & $\mathrm{X}^{2}$ Tabelado & $\mathrm{N}$ & $\mathrm{E}$ & $\begin{array}{c}\mathrm{X}^{2} \leq \\
\mathrm{X}^{2} \text { Tabelado }\end{array}$ & Classificação \\
\hline F & & $1: 1.000$ & $\mathrm{~A}$ & 0,17 & 54,090 & 42,91 & 26,80 & Verdadeiro & Aprovado \\
\hline$\delta_{0}^{50}$ & & & & & & $\underline{X}$ & $2^{2}$ & Condição & \\
\hline $\begin{array}{l}凶 \\
0\end{array}$ & Alt. & Escala & Classe & $\begin{array}{l}\mathrm{LP} \\
(\mathrm{m})\end{array}$ & $\mathrm{X}^{2}$ Tabelado & 2 & $\mathrm{Z}$ & $\begin{array}{c}\mathrm{X}^{2} \leq \\
\mathrm{X}^{2} \text { Tabelado }\end{array}$ & Classificação \\
\hline & & $1: 1.000$ & A & 0,17 & 52,949 & 94 & 15 & Falso & Reprovado \\
\hline
\end{tabular}


Também, com a amostra sem a presença de outliers aplicou-se a avaliação posicional utilizando o Decreto-Lei 89.817/ET-CQDG para a escala 1:1000 e classe A. Nos resultados, a imagem Sem PC foi reprovada na planimetria e altimetria, no entanto atenderia classe A na escala 1:10000 na planimetria e na escala 1:50000 na altimetria; as imagens PC Distribuídos e PC Agrupados foram aprovadas na planimetria e reprovadas na altimetria.

A análise da precisão através do teste de Qui-Quadrado divergiu da classificação do Decreto-Lei 89.817/ET-CQDG. Como esse método depende do DP e EP e as amostras sofreram redução no desvio padrão com a retirada de outilers, isso afetou o resultado principalmente na componente altimétrica das imagens Sem PC. Por isso, na avaliação posicional é importante adotar diversos critérios e procedimentos que avaliem a precisão e a tendência.

Para o teste de tendência, inicialmente aplicou-se o teste de normalidade Kolmogorov-Smirnov (Tabela 2). O valor de probabilidade apresentou não significativo para o nível de confiança 90\% para todas as amostras analisadas, exceto para a componente $\mathrm{Z}$ das imagens Sem PC, ou seja, a variável Z das imagens Sem PC não segue distribuição normal.

Tabela 2 - Resultados do teste de normalidade Kolmogorov-Smirnov para o nível de confiança $90 \%$

\begin{tabular}{|c|c|c|c|c|c|c|c|c|c|}
\hline 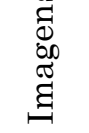 & $D_{t a b}$ & $\stackrel{D_{\max }}{\mathrm{N}}$ & $\begin{array}{l}\text { Resultado } \\
\text { N }\end{array}$ & $D_{t a b}$ & $\frac{D_{\max }}{\mathrm{E}}$ & $\begin{array}{l}\text { Resultado } \\
\text { E }\end{array}$ & $D_{t a b}$ & $D_{\max } \mathrm{Z}$ & $\begin{array}{c}\text { Resultado } \\
\text { Z }\end{array}$ \\
\hline 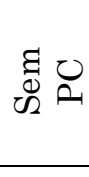 & 0,18 & 0,116 & $\begin{array}{c}\text { Seguem a } \\
\text { distribuição } \\
\text { normal. }\end{array}$ & 0,18 & 0,173 & $\begin{array}{c}\text { Seguem a } \\
\text { distribuição } \\
\text { normal. }\end{array}$ & 0,22 & 0,424 & $\begin{array}{c}\text { Não } \\
\text { seguem a } \\
\text { distribuição } \\
\text { normal. }\end{array}$ \\
\hline 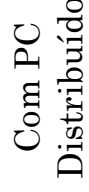 & 0,19 & 0,076 & $\begin{array}{c}\text { Seguem a } \\
\text { distribuição } \\
\text { normal. }\end{array}$ & 0,19 & 0,079 & $\begin{array}{c}\text { Seguem a } \\
\text { distribuição } \\
\text { normal. }\end{array}$ & 0,19 & 0,110 & $\begin{array}{c}\text { Seguem a } \\
\text { distribuição } \\
\text { normal. }\end{array}$ \\
\hline 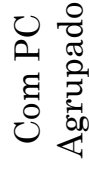 & 0,19 & 0,134 & $\begin{array}{c}\text { Seguem a } \\
\text { distribuição } \\
\text { normal. }\end{array}$ & 0,19 & 0,152 & $\begin{array}{c}\text { Seguem a } \\
\text { distribuição } \\
\text { normal. }\end{array}$ & 0,19 & 0,113 & $\begin{array}{c}\text { Seguem a } \\
\text { distribuição } \\
\text { normal. }\end{array}$ \\
\hline
\end{tabular}

Fonte: Elaborada pelos autores. 
Nas amostras com distribuição normal aplica-se o teste de tendência usando estatística inferencial. Como a componente $\mathrm{Z}$ das imagem Sem PC foi reprovada pelo Decreto-lei 89.817/ET-CQDG, por isso decidiu-se aplicar estatística inferencial em todos os dados. A regra de decisão considerando o nível de confiança de $90 \%$ foi: se $\left|z_{c a l}\right| \geq 1,645$ o dado é tendencioso; se $\left|z_{c a l}\right|<$ 1,645 o dado não é tendencioso. Os resultados indicam que os dados $\mathrm{N}$ e $\mathrm{E}$ das imagens PC Distribuídos e PC Agrupados não são tendenciosos (Tabela 3).

Tabela 3 - Resultados das análises de tendência

\begin{tabular}{c|c|c|c|c|c|c}
\hline Imagens & $\left|z_{c a l} E\right|$ & Resultado E & $\left|z_{c a l} N\right|$ & Resultado N & $\left|z_{c a l} Z\right|$ & Resultado Z \\
\hline Sem PC & 23,297 & Tendencioso & 5,253 & Tendencioso & 275,682 & Tendencioso \\
\hline $\begin{array}{c}\text { Com PC } \\
\text { Distribuídos }\end{array}$ & 1,613 & $\begin{array}{c}\text { Não } \\
\text { Tendencioso }\end{array}$ & 1,451 & $\begin{array}{c}\text { Não } \\
\text { Tendencioso }\end{array}$ & 8,615 & Tendencioso \\
\hline $\begin{array}{c}\text { Com PC } \\
\text { Agrupados }\end{array}$ & 0,876 & $\begin{array}{c}\text { Não } \\
\text { Tendencioso }\end{array}$ & 1,638 & $\begin{array}{c}\text { Não } \\
\text { Tendencioso }\end{array}$ & 5,201 & Tendencioso \\
\hline
\end{tabular}
Fonte: Elaborada pelos autores.

A análise de variância (ANOVA) é exibida na Tabela 4 e aponta que alguns tratamentos apresentam diferença significativa, visto que o valor $\mathrm{P}$ é menor que 0,1 (intervalo de confiança de 90\%) e o valor $\mathrm{F}$ é menor que $\mathrm{F}$ crítico. Assim, pode-se concluir que existe pelo menos uma discrepância do ponto de vista estatístico que difere da outra.

Tabela 4 - Resultado da ANOVA

\begin{tabular}{|c|c|c|c|c|c|c|}
\hline $\begin{array}{l}\text { Causas da } \\
\text { variação }\end{array}$ & $\begin{array}{c}\text { Graus de } \\
\text { liberdade } \\
\text { (GL) }\end{array}$ & $\begin{array}{c}\text { Soma dos } \\
\text { Quadrados } \\
\text { (SQ) }\end{array}$ & $\begin{array}{c}\text { Quadrado } \\
\text { Médio } \\
\text { (QM) }\end{array}$ & Valor F & $\begin{array}{c}\text { Valor } \\
\text { de F } \\
\text { crítico }\end{array}$ & Valor P \\
\hline \multicolumn{7}{|c|}{$\mathrm{N}$} \\
\hline Fator & 2 & 0,541 & 0,271 & 13,364 & 2,356 & $8,281^{*} 10^{-6}$ \\
\hline Resíduos & 90 & 1,822 & 0,020 & & & \\
\hline Total & 92 & 2,363 & & & & \\
\hline \multicolumn{7}{|c|}{$\mathrm{E}$} \\
\hline Fator & 2 & 28,304 & 14,152 & 535,463 & 2,356 & $1,059 * 10^{-50}$ \\
\hline Resíduos & 90 & 2,378 & 0,0264 & & & \\
\hline Total & 92 & 30,682 & & & & \\
\hline \multicolumn{7}{|c|}{$\mathrm{Z}$} \\
\hline Fator & 2 & 65,472 & 32,736 & 1563,639 & 2,412 & $3,389 * 10^{-58}$ \\
\hline Resíduos & 69 & 1,444 & 0,021 & & & \\
\hline Total & 71 & 66,916 & & & & \\
\hline
\end{tabular}


No Teste Tukey (Tabela 5), observa-se que valores $\mathrm{P}>0,05$ são não significativos, assim aceitamos a hipótese que discrepâncias na imagem Sem PC difere das PC Distribuídos e Agrupados. E isso indica que discrepâncias nas imagens PC Distribuídos e Agrupados são menores que na Sem PC.

Tabela 5 - Resultado das comparações múltiplas com o Teste Tukey

\begin{tabular}{c|c|c|c|c|c}
\hline \multirow{4}{*}{$\mathrm{N}$} & Fator & Sem PC & PC Distribuídos & PC Agrupados & Grupos \\
\cline { 2 - 6 } & Sem PC & & 0,0001139 & 0,001081 & $\mathrm{a}$ \\
\cline { 2 - 6 } & PC Distribuídos & 7,025 & & 0,4306 & $\mathrm{~b}$ \\
\cline { 2 - 6 } & PC Agrupados & 5,266 & 1,76 & & $\mathrm{~b}$ \\
\hline \multirow{4}{*}{$\mathrm{E}$} & Fator & Sem PC & PC Distribuídos & PC Agrupados & \\
\cline { 2 - 6 } & Sem PC & & 0,0001062 & 0,0001062 & $\mathrm{a}$ \\
\cline { 2 - 6 } & PC Distribuídos & 39,95 & & 0,9806 & $\mathrm{~b}$ \\
\cline { 2 - 6 } & PC Agrupados & 40,21 & 0,2674 & & $\mathrm{~b}$ \\
\hline \multirow{4}{*}{$\mathrm{Z}$} & Fator & Sem PC & PC Distribuídos & PC Agrupados & \\
\cline { 2 - 6 } & Sem PC & & 0,0001117 & 0,0001117 & $\mathrm{a}$ \\
\cline { 2 - 6 } & PC Distribuídos & 68,53 & & 0,9983 & $\mathrm{~b}$ \\
\cline { 2 - 6 } & PC Agrupados & 68,45 & 0,08182 & & $\mathrm{~b}$ \\
\hline \multicolumn{7}{|c|}{ Fonte: Elaborada pelos autores. } & \\
\hline
\end{tabular}

Os produtos dos testes realizados são apresentados na Tabela 6 .

Com os resultados percebeu-se que nas imagens PC Distribuídos e PC Agrupados as maiores discrepâncias foram em locais em que não haviam inseridos PC e valores do erro médio quadrático diminuíram ao se incluir PC.

Para análise de precisão, os resultados dos testes divergiram. Quando comparados, percebe-se que a classificação pelo Decreto-lei se apresenta mais rigorosa, visto que o teste Qui-Quadrado avalia apenas a variância em relação ao EP. Já para análise de tendência, os resultados mostraram que as discrepâncias das componentes planimétricas das imagens com PC Distribuídos e Agrupados não apresentam tendência. Assim, os resultados aprovaram as imagens PC Distribuídos e PC Agrupados na planimetria.

As imagens Sem PC na planimetria, Sem PC na altimetria, com PC Distribuídos na altimetria e PC Agrupados na altimetria foram reprovadas no teste de precisão e no de tendência para a escala 1:1.000. Assim, foi possível notar que quanto mais PC utilizados no processamento das fotos e quanto melhor distribuídos na região em estudo melhor foram as análises da avaliação da acurácia posicional. 
Tabela 6 - Resultados da avaliação da acurácia posicional

\begin{tabular}{|c|c|c|c|c|c|c|c|c|c|}
\hline \multirow{2}{*}{ Imagem } & \multicolumn{3}{|c|}{ Sem PC } & \multicolumn{3}{|c|}{ Com PC Distribuídos } & \multicolumn{3}{|c|}{ Com PC Agrupados } \\
\hline & $\mathrm{E}$ & $\mathrm{N}$ & $\mathrm{Z}$ & $\mathrm{E}$ & $\mathrm{N}$ & $\mathrm{Z}$ & $\mathrm{E}$ & $\mathrm{N}$ & $\mathrm{Z}$ \\
\hline Média & 1,231 & 0,219 & 2,244 & 0,059 & 0,054 & 0,179 & 0,069 & 0,108 & 0,251 \\
\hline $\mathrm{DP}$ & 0,249 & 0,210 & 0,045 & 0,039 & 0,041 & 0,065 & 0,068 & 0,065 & 0,220 \\
\hline EMQ & 1,269 & 0,305 & 2,283 & 0,071 & 0,069 & 0,127 & 0,098 & 0,127 & 0,336 \\
\hline $\begin{array}{c}\mathrm{N}^{\circ} \cdot \text { de } \\
\operatorname{amostras}(\mathrm{n})\end{array}$ & 47 & 47 & 30 & 40 & 40 & 42 & 42 & 42 & 41 \\
\hline $\begin{array}{c}\text { Dado é } \\
\text { tendencioso? }\end{array}$ & Sim & Sim & Sim & Não & Não & Sim & Não & Não & Sim \\
\hline $\begin{array}{c}\text { EM }(1: 1.000 \\
\text { - Classe A) } \\
\end{array}$ & 0,28 & 0,28 & 0,27 & 0,28 & 0,28 & 0,27 & 0,28 & 0,28 & 0,27 \\
\hline $\begin{array}{c}\mathrm{EP}(1: 1.000- \\
\text { Classe A) }\end{array}$ & 0,17 & 0,17 & 0,17 & 0,17 & 0,17 & 0,17 & 0,17 & 0,17 & 0,17 \\
\hline$\%$ disc. $<\mathrm{EM}$ & $0 \%$ & $0 \%$ & $0 \%$ & $100 \%$ & $100 \%$ & $70 \%$ & $95,2 \%$ & $95,2 \%$ & $63,4 \%$ \\
\hline $\mathrm{EMQ}<\mathrm{EP}$ & Não & Não & Não & Sim & Sim & Não & Sim & Sim & Não \\
\hline $\begin{array}{c}\text { Aprovado } \\
\text { ET-CQDG } \\
(1: 1.000) \\
\end{array}$ & Não & Não & Não & $\operatorname{Sim}$ & Sim & Não & Sim & Sim & Não \\
\hline$X_{\text {cal }}^{2}$ & 408,22 & 187,02 & 2,06 & 12,74 & 12,03 & 24,57 & 26,80 & 42,91 & 94,15 \\
\hline$X^{2}{ }_{t a b}(90 \%)$ & 59,774 & 59,774 & 40,256 & 51,805 & 51,805 & 54,09 & 54,09 & 54,09 & 52,949 \\
\hline $\begin{array}{c}X^{2}{ }_{c a l} \\
<X^{2}{ }_{t a b}(90 \%)\end{array}$ & Não & Não & Sim & Sim & Sim & Sim & Sim & Sim & Não \\
\hline $\begin{array}{c}\text { Dado é } \\
\text { preciso? }\end{array}$ & Não & Não & Não & Sim & Sim & Não & Sim & Sim & Não \\
\hline $\begin{array}{c}\text { Dado é } \\
\text { acurado? }\end{array}$ & Não & Não & Não & $\operatorname{Sim}$ & Sim & Não & Sim & Sim & Não \\
\hline
\end{tabular}

Fonte: Elaborada pelos autores.

Alguns fatores podem ter influenciado nos resultados, principalmente da componente altimétrica. Primeiramente, os produtos obtidos Sem PC estão vinculados à precisão do GNSS de navegação da aeronave, portanto possuirão erros compatíveis com esse sistema de posicionamento, os quais na altimetria são cerca de 3 vezes maiores que na planimetria; caso usássemos outra tecnologia GNSS com sistema inercial de alta precisão na ARP conseguiríamos resultados próximos aos obtidos com os receptores GNSS utilizados em solo. Outro fator é o processo de geração do MDT testado o qual passa por diversos processos de filtragem e interpolação. O MDT foi gerado através do MDS, assim é realizado um processo de filtragem para remover os objetos acima do solo e a superfície é construída através do processo de interpolação dos pontos, o que influencia no resultado final. 
Outro fator que pode ter influenciado nos resultados é a característica da aeronave utilizada. Com o avanço tecnológico diversas melhorias são aplicadas na qualidade da câmera, na estabilização, na precisão do GNSS e sistema inercial da aeronave o que ajuda na captura de imagens para o mapeamento aéreo e influencia a precisão de dados obtidos. Como nesse trabalho optou-se por uma aeronave de baixo custo e com características de sistema de imageamento inferiores a várias tecnologias existentes no mercado, como por exemplo, não poder sobrevoar a velocidade do vento superior a $10 \mathrm{~m} / \mathrm{s}$, possuir sensor óptico que captura fotos em 12 megapixels e GNSS de navegação, a precisão dos resultados obtidos sofreu interferência da qualidade dos parâmetros da ARP utilizada quando comparados com a precisão dos equipamentos utilizados em solo.

\section{Conclusões}

A discussão desse estudo é considerada para o mapeamento topográfico em grande escala usando ARP de baixo custo e a possibilidade de utilização na cartografia cadastral de parcelas urbanas. Ao longo da pesquisa percebeuse a falta de critérios técnicos de mensuração ainda não definidos no Brasil. Além das legislações e de uma rede cadastral para integrar o sistema é importante verificar métodos de obtenção de dados para compor o cadastro.

Diante dos resultados obtidos conclui-se que a metodologia aplicada funciona e as imagens geradas utilizando PC mostrou-se consistente para a produção de dados quantitativos e qualitativos para as ações de geração de mapeamento topográfico em grande escala. É importante salientar que se deve aplicar a avaliação da acurácia de todo produto que se for gerar.

As informações geradas, no contexto do cadastro, poderão servir de base e referência espacial à representação da parcela e fornecer informações à sua caracterização para compor a cartografia cadastral e auxiliar o registro de imóveis; além disso, poderá auxiliar a gestão fundiária, melhorar a análise de uso e ocupação do solo e auxiliar as equipes nos serviços feitos em campo. 
Como aspectos positivos destaca-se que o uso da ARP pode ser considerado para mapeamento urbano, sendo capaz de obter produtos com qualidade cartográfica aceitável, permitindo a identificação de edificações e estradas, além de possuir vantagem na economia de tempo e após processamento gerar uma gama de informações. Devido a área ser pequena fez-se apenas um voo utilizando uma bateria e a aeronave teve operação tranquila e executou o voo de maneira rápida.

Por outro lado, a ARP utilizada enfrenta uma série de questões negativas, como os riscos de quedas, pequena autonomia, pouca estabilidade, pouca qualidade da câmera e sistema de posicionamento, longo tempo de processamento (nesse experimento, foram cerca de 6 horas de processamento para cada grupo de imagens) que envolvem também alto custo computacional.

Como recomendações a trabalhos futuros, têm-se: Usar outros modelos de ARP; Verificar o padrão de distribuição espacial das amostras através de análises espaciais; Executar processamento das fotos utilizando outros softwares; Avaliar a acurácia através de métodos por feições lineares e áreas.

\section{Agradecimentos}

Este estudo contou com o incentivo da Universidade Federal de Uberlândia, por meio do Programa de Pós-Graduação do Instituto de Geografia e da Faculdade de Engenharia Civil, que disponibilizaram seus equipamentos, instalações e aplicativos computacionais. O presente trabalho foi realizado com apoio do Conselho Nacional de Desenvolvimento Científico e Tecnológico (CNPq) com o processo 132269/2017-1.

\section{Contribuição dos autores}

Definição da problemática e definição dos procedimentos metodológicos (OLIVEIRA, D. V. e BRITO, J. L. S.), aquisição e processamento dos dados, revisão de literatura, organização e escrita do texto, produção e organização 
dos mapas e gráficos, aplicação de técnicas estatísticas e matemáticas (OLIVEIRA, D. V.).

\section{Referências}

ABNT, Associação Brasileira de Normas Técnicas: NBR 13.133. Associação Brasileira de Normas Técnicas. Execução de Levantamento Topográfico. Rio de Janeiro, 1994.

ANAC, Agência Nacional de Aviação Civil. Regulamentação da ANAC sobre drones completa um ano em vigor. Notícias. Publicado em abr. 2018. Site <http://www.anac.gov.br/noticias/regulamentacao-da-anac-sobredrones-completa-um-ano-em-vigor>, acessado em abril de 2018.

ANTUNES, A. F. B.; HOLLATZ, R. C. V. Cadastro Técnico Multifinalitário de baixo custo utilizando VANT (veículo aéreo não tripulado). Anais do Simpósio Brasileiro de Sensoriamento Remoto, João Pessoa, 2015. pp. 5858- 5864. Site <http://www.dsr.inpe.br/sbsr2015/files/p1205.pdf>, acessado em fevereiro de 2018.

BRASIL. Decreto N 89.817, de 20 de junho de 1984. Estabelece as instruções reguladoras das normas técnicas da cartografia nacional. Diário Oficial da União, Brasília, 1984.

BRASIL. Lei № 10.257, de 10 de julho de 2001. Regulamenta os arts. 182 e 183 da Constituição Federal, estabelece diretrizes gerais da política urbana e dá outras providências. Diário Oficial da União, Brasília, 2001.

BRASIL. Portaria Ministerial n ${ }^{0} 511$, de 07 de dezembro de 2009. Diretrizes para a criação, instituição e atualização do Cadastro Técnico Multifinalitário (CTM) nos municípios brasileiros. Ministério das Cidades, Diário Oficial da União, 2009.

BRASIL. Especificação Técnica Para a Aquisição de Dados Geoespaciais Vetoriais (ET-ADGV). Diretoria do Serviço Geográfico. Departamento de Ciência e Tecnologia do Exército Brasileiro. 2ª Edição. Brasília, 2011. 
BRASIL. Normas da Especificação Técnica para Controle de Qualidade de Dados Geoespaciais (ET-CQDG). Diretoria de Serviço Geográfico. $1^{\mathrm{a}}$ Edição, Brasília, 2016.

DALMOLIN, Q. Ajustamento por mínimos quadrados. $2^{\mathrm{a}}$ ed. Curitiba: Editora UFPR, 2004. 175 p. ISBN: 8588783029.

DJI. PHANTOM 3 ADVANCED. Manual do Usuário. 2015. v. 1. 59 p.

EICK, V. The droning of the drones: the increasingly advanced technology of surveillance and control. Statewatch analysis, v. 12, n. 21/10, 2010. Site <http://www.statewatch.org/analyses/no-106-the-droning-ofdrones.pdf>, acessado em fevereiro de 2018.

FAN, H. Theory of errors and least squares adjustment. Royal Institute of Technology (KTH): Division of Geodesy and Geoinformatics, Stockholm (Sweden), Geodesy Report. ISBN: 9171702008, 2010.

FARIAS, A. R.; MINGOTE, R.; VALLE, L. B.; SPADOTTO, C.A.; LOVISI FILHO, E. Identificação, mapeamento e quantificação das áreas urbanas do Brasil. Embrapa Gestão Territorial - Comunicado Técnico (INFOTECA-E), Campinas, SP, 2017. ISSN 2317-8787. Site $<$ https://ainfo.cnptia.embrapa.br/digital/bitstream/item/176016/1/20170 522-COT-4.pdf $>$, acessado em outubro de 2017.

FONSECA NETO, F.de D.; GRIPP JÚNIOR, J.; BOTELHO, M. F.; SANTOS, A. de P. dos; NASCIMENTO, L. A.; FONSECA, A. L. B. Avaliação da qualidade posicional de dados espaciais gerados por VANT utilizando feições pontuais e lineares para aplicações cadastrais. Boletim de Ciências Geodésicas, v. 23, p. 134-149, 2017. ISSN 1982-2170. https://doi.org/10.1590/s1982-21702017000100009

GALO, M.; CAMARGO, P.O. Utilização do GPS no controle da qualidade de carta. Anais do Congresso Brasileiro de Cadastro Técnico Multifinalitário. Florianópolis, 1994, pp. 41-48. Site $<$ https://www.researchgate.net/publication/265208956_Utilizacao_do_G PS_no_controle_de_qualidade_de_cartas>, acessado em agosto de 2018. 
GEMAEL, C. Introdução ao ajustamento de observações: aplicações geodésicas. Curitiba: UFPR, 1994. 319 p. ISBN: 8585132922.

GIBBONS, J. D.; CHAKRABORTI, S. Nonparametric statistical inference. $4^{\mathrm{a}}$ ed., revised and expanded, 2003. 672 p. Site <http://erecursos.uacj.mx/bitstream/handle/20.500.11961/2064/Gibbons $\% 2 \mathrm{C} \% 202003$.pdf? sequence=14\&isAllowed $=\mathrm{y}>$, acessado em agosto de 2018.

GHILANI, C. D.; WOLF, P. R. Adjustment computations: spatial data analysis. $4^{\mathrm{a}}$ ed., New York: Jonh Wiley \& Sons, 2006. https://doi.org/10.1002/9780470121498.

HAIR JÚNIOR, J. F.; BLACK, W. C.; BABIN, B. J.; ANDERSON, R. E.; TATHAM, R. L. Análise Multivariada de Dados. $6^{a}$ ed. Porto Alegre: Bookman, 2009. ISBN 0130329290.

IBGE, Instituto Brasileiro de Geografia e Estatística. Pesquisa Nacional por Amostra de Domicílios: síntese de indicadores 2014, Rio de Janeiro, 102 p., 2015. ISBN 978-85-240-4365-9. Site <https://biblioteca.ibge.gov.br/visualizacao/livros/liv94935.pdf>, acessado em outubro de 2017.

IBGE, Instituto Brasileiro de Geografia e Estatística. Agência IBGE Notícias, Rio de Janeiro, 30 ago. 2017. Site <https://agenciadenoticias.ibge.gov.br/16131-ibge-divulga-asestimativas-populacionais-dos-municipios-para-2017>, acessado em janeiro de 2018.

IBGE, Instituto Brasileiro de Geografia e Estatística. IBGE Cidades. 2018. Site < https://cidades.ibge.gov.br>, acessado em janeiro de 2018.

MIKHAIL, E.; ACKERMAN, F. Observations and Least Squares. University Press of America, 1976. 497 p. ISBN: 0819123978.

MONTGOMERY, D. C.; RUNGER, G. C. Applied Statistics and Probability for Engineers. $3^{\mathrm{a}}$ ed. New York: John Wiley \& Sons, 2002. 976 p. Site <http://www.um.edu.ar/math/montgomery.pdf>, acessado em fevereiro de 2018. 
PELEGRINA, M. A.; CANAL, M. A.; JULIAO, R. P.; OBAL, K. K. Avaliação da qualidade geométrica de produtos cartográficos levantados por VANT aplicados ao cadastro predial em município de pequeno porte no brasil. Anais do I Seminário Internacional UAV, Lisboa, 2016. pp. 37-48. ISBN: 978-989-20-6726-1. URI: http://hdl.handle.net/10362/37911.

RIJSDIJK, M; VAN HINSBERGH, W.H.M; WITTEVEEN, W.; TEN BUUREN, G.H.M.; SCHAKELAAR, G.A.; POPPING, G.; VAN PERSIE, M.; LADIGES, R. Unmanned Aerial Systems in the process of Juridical Verification of Cadastral Border. Proceedings of International Archives of the Photogrammetry, v. XL-1/W2, 2013, Rostock, Germany. p. 325 - 331. Site <https://www.int-arch-photogramm-remotesens-spatial-inf-sci.net/XL-1-W2/325/2013/isprsarchives-XL-1-W2-3252013.pdf $>$, acessado em Agosto de 2017.

VOLKMANN, W.; BARNES, G. Virtual surveying: Mapping and modeling cadastral boundaries using Unmanned Aerial Systems (UAS). Proceedings of the FIG Congress: Engaging the Challenges Enhancing the Relevance, Kuala Lumpur, Malaysia, 16-21 June 2014, p. $1-13$.

Site <http://www.fig.net/resources/proceedings/fig_proceedings/fig2014/pa pers/ts09a/TS09A_barnes_volkmann_7300.pdf>, acessado em junho de 2017. 